\title{
Integrated control of hypertension by olmesartan medoxomil and hydrochlorothiazide and rationale for combination
}

This article was published in the following Dove Press journal:

Integrated Blood Pressure Control

6 December 201I

Number of times this article has been viewed

\section{Henry A Punzi}

Trinity Hypertension and Metabolic Research Institute, Punzi Medical Center, Carrollton, TX, USA;

Department of Family and Community Medicine, UT Southwestern Medical

Center, Dallas, TX, USA
Correspondence: Henry A Punzi

Punzi Medical Center, 1932 Walnut Plaza,

Carrollton, TX 75006, USA

$\mathrm{Tel}+\mathrm{I} 9724787700$

Fax + I 972478770 I

Email punzimedcenter@aol.com

\begin{abstract}
Hypertension affects nearly one-third of all individuals in the US, yet one-half of all treated patients achieve blood pressure (BP) controlled to recommended goals. The percentage of patients with uncontrolled BP is likely to be much higher when considering the number of patients who are not even aware of their hypertensive state. Elevated BP is associated with increased risks of cardiovascular events and end-organ damage. Antihypertensive monotherapy is not always sufficient to achieve BP goals, and thus more aggressive treatment regimens need to be considered. Antihypertensive combination therapy, which may improve tolerability, offers the benefit of targeting different mechanisms of action. Numerous outcomes studies support the use of a renin-angiotensin system inhibitor as a first-line choice in antihypertensive therapy. This review discusses the benefits of combination therapy with the angiotensin type II receptor blocker olmesartan medoxomil (OM) paired with the thiazide diuretic hydrochlorothiazide (HCTZ). The pharmacokinetic properties of OM will be reviewed in addition to efficacy studies that support $\mathrm{OM}+\mathrm{HCTZ}$ combination therapy over other possible antihypertensive combinations. Finally, a rationale for choosing HCTZ over another diuretic, chlorthalidone, will also be discussed based on pharmacokinetic differences, clinical concerns, and trends in use.
\end{abstract}

Keywords: antihypertensives, blood pressure, combination therapy, HCTZ

\section{Introduction}

Hypertension, a highly prevalent condition that affects $29 \%$ of the population in the $\mathrm{US},{ }^{1}$ is a modifiable risk factor for cardiovascular (CV) morbidity and mortality, stroke, and renal failure. ${ }^{2}$ Indeed, there is a linear correlation between blood pressure (BP) and the risk of death from ischemic heart disease and stroke, regardless of age; this risk is doubled for each 20- or 10-mmHg increase in systolic BP (SBP) and diastolic BP (DBP), respectively. ${ }^{3}$ An increasing number of patients with hypertension in the US are receiving treatment. However, approximately $50 \%$ of patients receiving treatment fail to attain recommended BP goals of $<140 / 90 \mathrm{mmHg}$ or $<130 / 80 \mathrm{mmHg}$ for patients with diabetes mellitus or chronic renal disease. ${ }^{1}$ Current practice guidelines are based on clinical trial evidence, demonstrating that treating patients with hypertension to defined BP thresholds, or goals, improves long-term outcomes. ${ }^{3}$ Achieving BP control in a greater proportion of patients with hypertension will require treating more patients, treating them earlier, and intensifying their therapy when treatment goals are unmet.

An important component of ensuring successful treatment is the use of more aggressive treatment strategies. BP goals are reached in only one-third of patients receiving monotherapy. ${ }^{4-6}$ As a result, combination therapy is required to achieve recommended 
BP goals in the majority of patients with hypertension, particularly those with stage 2 hypertension, and treatment guidelines emphasize the importance of starting antihypertensive combination therapy in patients with a BP level that exceeds the goal by $>20 / 10 \mathrm{mmHg}^{3}$

Combination therapy should comprise different classes of agents with complementary mechanisms of action, which may provide an antihypertensive effect greater than either component alone, and with a favorable tolerability profile. ${ }^{3}$ Blockade of the renin-angiotensin system (RAS) pathway by angiotensin type II receptor blockers (ARBs) provides an antihypertensive effect that can be enhanced by the addition of hydrochlorothiazide (HCTZ). ${ }^{7}$ HCTZ acts in the kidney by blocking the reabsorption of sodium and chloride in the distal portion of the kidney tubule. ${ }^{8}$ In addition, HCTZ is believed to have direct (vasodilation) or indirect effects on the blood vessel itself, although the exact mechanism explaining this is unknown. ${ }^{9}$ Use of HCTZ alone causes volume contraction that has been shown to cause an increase in RAS pathway activity to compensate. ${ }^{7}$ The synergistic addition of a RAS inhibitor to HCTZ blunts this physiological response to diuresis, thereby achieving volume contraction with decreased RAS activity. ${ }^{7}$

ARBs are a well tolerated drug class. Olmesartan medoxomil (OM) is a widely prescribed ARB that has been shown in some head-to-head studies to have greater BP-lowering efficacy than older ARBs such as losartan potassium (LOS), ${ }^{10,11}$ valsartan, and irbesartan. ${ }^{10}$ In a 12 -week randomized, double-blind, forced-titration study, patients received LOS, OM, or valsartan. ${ }^{12}$ At week 8 , reductions in seated cuff DBP (SeDBP) were significantly greater in the OM 40-mg group compared with the LOS group (100 mg once daily). By week 12, however, there were no significant differences in BP-lowering efficacy between OM (40 mg), valsartan (320 mg), and LOS (50 mg twice daily). In a subgroup analysis of this study in Black patients, OM demonstrated greater efficacy by week 8 compared with LOS; however, all drugs had similar antihypertensive effects by week $12 .{ }^{13}$ Recently, the newest member of the ARB family, azilsartan medoxomil, which has been approved for use in the US, has superior efficacy at its highest dose compared with OM and valsartan. ${ }^{14}$

Pharmacokinetic differences such as higher angiotensin II receptor type $1\left(\mathrm{AT}_{1}\right)$ receptor affinity, longer terminal elimination half-life, and slower $\mathrm{AT}_{1}$ receptor disassociation help contribute to the efficacy of OM. ${ }^{15,16}$ This article briefly reviews the efficacy and safety of combining the ARB OM with HCTZ in the management of hypertension and provides an update on current findings from recent clinical studies.

\section{OM/HCTZ: pharmacokinetics and pharmacodynamics}

$\mathrm{OM}$ is a prodrug that is hydrolyzed in the gastrointestinal tract to form its active metabolite, olmesartan. ${ }^{17}$ Once absorbed, the metabolite does not undergo further changes, and 35\%-50\% of the absorbed dose is excreted in the urine. ${ }^{17}$ Peak plasma concentrations are achieved in 1-2 hours, followed by an elimination half-life of 13 hours. ${ }^{17}$ Steady-state plasma concentrations are achieved in 3-5 days with once-daily dosing. ${ }^{17}$ HCTZ is not metabolized and is rapidly eliminated by the kidney, with a plasma half-life between 5.6 and 14.8 hours. ${ }^{17}$ No significant pharmacokinetic drug-drug interactions occur when OM and HCTZ are coadministered. ${ }^{18}$ The pharmacokinetics of OM $20 \mathrm{mg}+$ HCTZ $25 \mathrm{mg}$ in healthy subjects were similar to OM and HCTZ monotherapy at the same doses with regards to area underneath the concentration-time curve and maximum plasma concentration values at steady state and time to maximum plasma concentration values. ${ }^{18}$

$\mathrm{OM}$ selectively binds the $\mathrm{AT}_{1}$ receptor with high affinity, slow disassociation, and a high degree of insurmountable antagonism. ${ }^{15} \mathrm{OM}$ is a more potent inhibitor of angiotensin II receptor binding than LOS and its active metabolite ${ }^{19}$ and dissociates from the receptor more slowly than telmisartan. ${ }^{15}$ $\mathrm{OM}$ inhibits the pressor effects of angiotensin I at doses of 2.5-40 mg; this inhibitory effect is dose-dependent. ${ }^{17} \mathrm{HCTZ}$ combined with OM causes diuresis to begin within 2 hours of administration and peaks at approximately 4 hours, with a duration of 6-12 hours. ${ }^{17}$

\section{Efficacy of OM and HCTZ combination therapy}

Several studies have demonstrated the efficacy of OM+HCTZ for lowering BP and enabling the achievement of BP goals. A summary of OM + HCTZ efficacy studies are presented in Table 1.

In a multicenter, randomized, double-blind factorial design study, 502 patients were assigned to placebo, OM monotherapy (10, 20, or $40 \mathrm{mg} /$ day), HCTZ monotherapy (12.5 or $25 \mathrm{mg}$ ), and $\mathrm{OM} / \mathrm{HCTZ}$ combination therapy $(10 / 12.5,10 / 25,20 / 12.5,20 / 25,40 / 12.5$, and $40 / 25 \mathrm{mg}$ ). All six combinations of OM + HCTZ produced statistically significant reductions in BP from baseline relative to placebo, and all $\mathrm{OM}+\mathrm{HCTZ}$ combinations had greater $\mathrm{BP}$ reductions than their individual components. ${ }^{20} \mathrm{The}$ $\mathrm{BP}$ reduction achieved at the maximum dose of $\mathrm{OM} / \mathrm{HCTZ}$ 
Table I Clinical trials assessing the antihypertensive efficacy of OM/HCTZ combination therapy

\begin{tabular}{|c|c|c|c|c|c|}
\hline Study & Patients (N) & Dosage (daily) & $\begin{array}{l}\text { Baseline SeBP } \\
(\mathrm{mmHg})\end{array}$ & $\begin{array}{l}\text { SeSBP/SeDBP reduction } \\
(\mathrm{mmHg})\end{array}$ & $\begin{array}{l}\% \text { achieved } \\
\text { SeBP target }\end{array}$ \\
\hline & & & & & SeSBP $<140 \mathrm{mmHg}$ \\
\hline \multirow[t]{5}{*}{ Chrysant et $\mathrm{al}^{20}$} & 502 & PLA & $152.1 / 103.4$ & $3.3 / 8.2$ & 33.3 \\
\hline & & OM $40 \mathrm{mg}$ & $152.9 / 102.6$ & $16.0 / 14.6$ & 60.0 \\
\hline & & HCTZ 25 mg & $155.9 / 104.4$ & $17.1 / 12.9$ & 67.4 \\
\hline & & OM/HCTZ 40/25 mg & $153.6 / 103.4$ & $26.8 / 21.9$ & 87.2 \\
\hline & & & & & $\mathrm{SeBP}<140 / 90 \mathrm{mmHg}$ \\
\hline \multirow[t]{3}{*}{ Kereiakes et $\mathrm{a}^{21}$} & 191 & BEN/AML 20/10 mg & $169.6 / 101.4$ & $26.5 /{ }^{\mathrm{a}}$ & 44.7 \\
\hline & & OM/HCTZ 40/25 mg & $167.0 / 101.7$ & $32.5 /^{\mathrm{a}}$ & 66.3 \\
\hline & & & & & SeBP $<140 / 90 \mathrm{mmHg}$ \\
\hline \multirow[t]{3}{*}{ Oparil et a ${ }^{22}$} & 278 & PLA & I55.3/93.7 & $0.1 /+0.8$ & 30.7 \\
\hline & & OM/HCTZ 40/25 mg & $156.9 / 94.2$ & $22.3 / 12.1$ & 74.1 \\
\hline & & & & & $\mathrm{SeBP}<140 / 90 \mathrm{mmHg}$ \\
\hline \multirow[t]{2}{*}{ Kereiakes et al ${ }^{38}$} & 178 & $\mathrm{OM} / \mathrm{HCTZ} 40 / 25 \mathrm{mg}$ & $165.5 / 87.7$ & $25.4 / 10.5$ & 67.0 \\
\hline & & & & & $\begin{array}{l}\text { SeBP }<140 / 90 \mathrm{mmHg} \\
(<130 / 80 \mathrm{mmHg} \text { forT2DM })\end{array}$ \\
\hline \multirow[t]{2}{*}{ Rump et $\mathrm{a}^{24}$} & 1226 & $\mathrm{OM} / \mathrm{HCTZ} 40 / 25 \mathrm{mg}$ & $155.4 / 98.0^{\mathrm{b}}$ & $30.3 / 19.0$ & 42.1 \\
\hline & & & & & SeBP $<130 / 80 \mathrm{mmHg}$ \\
\hline $\begin{array}{l}\text { Kereiakes and } \\
\text { Neutel }^{40}\end{array}$ & $192^{c}$ & $\mathrm{OM} / \mathrm{HCTZ} 40 / 25 \mathrm{mg}$ & |58.|/90.0 & $21.8 / 9.9$ & 41.1 \\
\hline
\end{tabular}

Notes: aDBP reductions not reported; bbaseline at end of OM $40 \mathrm{mg}$ run-in period; call patients with T2DM.

Abbreviations: AML, amlodipine; BEN, benazepril; BP, blood pressure; DBP, diastolic blood pressure; HCTZ, hydrochlorothiazide; OM, olmesartan medoxomil; PLA, placebo; SBP, systolic blood pressure; SeBP, seated cuff blood pressure; SeDBP, seated cuff diastolic blood pressure; SeSBP, seated cuff systolic blood pressure; T2DM, type 2 diabetes mellitus.

40/25 mg was 26.8/21.9 $\mathrm{mmHg}$ from a baseline BP of 153.6/103.4 mmHg. This study reported individual SBP and DBP goals, and at the maximum OM/HCTZ 40/25 mg dose, $87.2 \%$ achieved SBP $<140 \mathrm{mmHg}$, while $79.5 \%$ achieved DBP $<90$ mmHg. $^{20}$

A multicenter, double-blind study by Kereiakes et al randomized 191 patients with stage 2 hypertension to an $\mathrm{OM}+\mathrm{HCTZ}$ or benazepril $(\mathrm{BEN})+$ amlodipine (AML) combination treatment regimen for 12 weeks. ${ }^{21}$ Doses were up-titrated in a stepwise fashion from OM or BEN monotherapy if BP was $\geq 120 / 80 \mathrm{mmHg}$. Titration steps in the OM treatment group were OM $20 \mathrm{mg}, \mathrm{OM} 40 \mathrm{mg}, \mathrm{OM} /$ HCTZ 40/12.5 mg, and OM/HCTZ 40/25 mg, while titration steps in the BEN treatment group were BEN $10 \mathrm{mg}, \mathrm{BEN}$ $20 \mathrm{mg}$, BEN/AML 20/5 mg, and BEN/AML 20/10 mg. The OM + HCTZ treatment arm was associated with a greater reduction in SBP from baseline than BEN + AML at $32.5 \mathrm{mmHg}$ vs $26.5 \mathrm{mmHg}(P<0.024) .{ }^{21}$ A cumulative BP goal of $<140 / 90 \mathrm{mmHg}$ was achieved by $66.3 \%$ of patients treated with $\mathrm{OM}+\mathrm{HCTZ}$ compared with $44.7 \%$ of patients in the BEN + AML treatment arm $(P<0.006) .{ }^{21}$

The Benicar Efficacy: New Investigative Findings Showed Olmesartan Medoxomil Safely and Effectively Reduced Blood Pressure Compared With Placebo in a Clinical Evaluation of Patients With Stage 1 and Stage 2 Hypertension (BENIFORCE) study was a 12-week, randomized, double-blind, placebo-controlled, titration study in 276 patients with stage 1 or stage 2 hypertension. ${ }^{22}$ Patients were randomized to placebo or an $\mathrm{OM}$ treatment regimen for a period of 12 weeks. If BP was $\geq 120 / 80 \mathrm{mmHg}$, patients were up-titrated in a stepwise fashion from monotherapy to a maximum of OM/HCTZ 40/25 mg. The titration steps were OM $20 \mathrm{mg}$, OM $40 \mathrm{mg}$, OM/HCTZ 40/12.5 mg, and OM/ HCTZ 40/25 mg. The OM-based treatment regimen provided significantly greater least-squares mean reductions in seated BP (SeBP) from baseline compared with placebo $(22.3 / 12.1$ vs $0.1 /-0.8 \mathrm{mmHg} ; P<0.0001) .{ }^{22}$ The achievement rate of a cumulative BP goal of $<140 / 90 \mathrm{mmHg}$ was significantly higher in OM-based treatment vs placebo recipients $(74.1 \%$ vs $30.7 \% ; P<0.0001) .{ }^{22}$ Furthermore, BP normalization $(<120 / 80 \mathrm{mmHg})$ was also achieved by more patients treated with the OM-based regimen vs placebo (27.3\% vs $1.5 \%$; $P<0.0001$ ) (Figure 1). ${ }^{22}$ Recently, a subgroup analysis of BENIFORCE indicated that the significant improvements in BP lowering were achieved with OM-based therapy vs placebo, regardless of race, age, or sex (Figure 2). ${ }^{23}$

A recent European study investigated the safety and tolerability of OM/HCTZ in 1226 patients with stage 2 hypertension. ${ }^{24}$ Patients entered an 8-week open-label period and were treated with OM $40 \mathrm{mg}$ per day. Patients who failed to achieve BP control (trough seated cuff SBP [SeSBP] of 140-180 $\mathrm{mmHg}$ and SeDBP of 90-115 mmHg, 
and mean 24-hour DBP $\geq 80 \mathrm{mmHg}$ and $\geq 30 \%$ of daytime DBP $>85 \mathrm{mmHg}$ ) entered a randomized double-blind treatment phase of 8 weeks. Patients were randomized in a 2:2:2:1 scheme to OM $40 \mathrm{mg}, \mathrm{OM} / \mathrm{HCTZ} 20 / 12.5 \mathrm{mg}$, OM/HCTZ 40/12.5 mg, and OM/HCTZ 40/25 mg. The primary endpoint was the change from baseline in SeDBP from week 8 to the end of week 16 . For the primary endpoint for the highest dosage of OM/HCTZ 40/25 mg, the change in SeDBP was $-11.2 \mathrm{mmHg}$ compared with $-5.7 \mathrm{mmHg}$ for patients who remained on OM $40 \mathrm{mg}(P<0.0001)$. The change in SeSBP for the same time period was $-16.2 \mathrm{mmHg}$ for OM/HCTZ 40/25 mg compared with $-8.9 \mathrm{mmHg}$ for OM
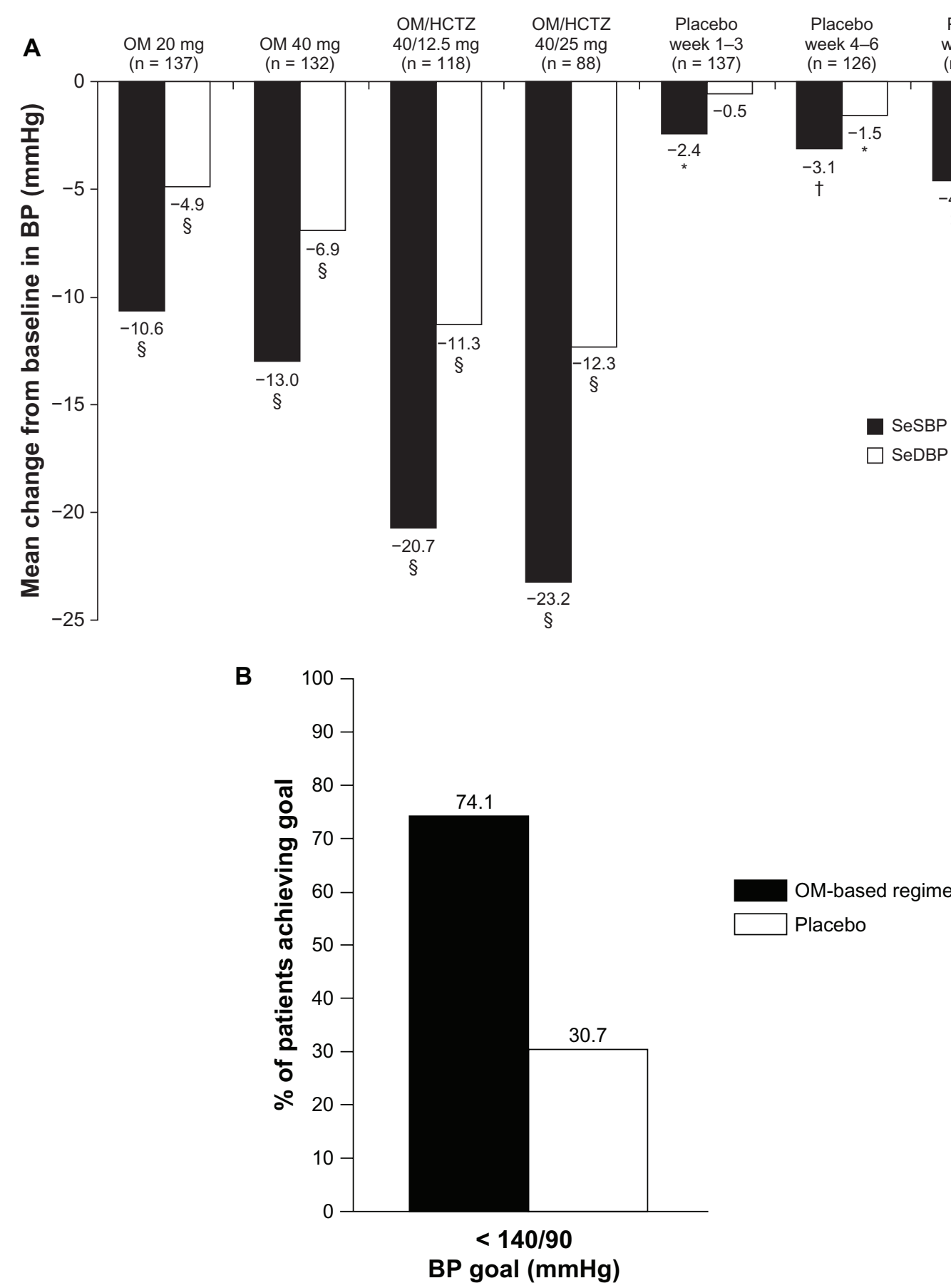

Figure I Efficacy results from the BENIFORCE trial. (A) Mean change from baseline to week 12 or last observation carried forward in seated cuff BP by titration step in the total efficacy cohort. (B) Proportion of patients who achieved BP $<140 / 90 \mathrm{mmHg}$ in the total efficacy cohort. ${ }^{22}$

Note: $* P<0.05,+P<0.01,{ }^{\dagger} P<0.001,{ }^{\$} P<0.000$ I for within-group comparisons between study baseline and end of treatment using paired $t$-test.

Reprinted from Oparil et al. J Clin Hypertens (Greenwich). 2008; I0(12):91 I-921, with permission from John Wiley and Sons, copyright @ 2008.

Abbreviations: BENIFORCE, Benicar Efficacy: New Investigative Findings Showed Olmesartan Medoxomil Safely and Effectively Reduced Blood Pressure Compared With Placebo in a Clinical Evaluation of Patients With Stage I and Stage 2 Hypertension; BP, blood pressure; HCTZ, hydrochlorothiazide; OM, olmesartan medoxomil; SeDBP, seated cuff diastolic blood pressure; SeSBP, seated cuff systolic blood pressure. 


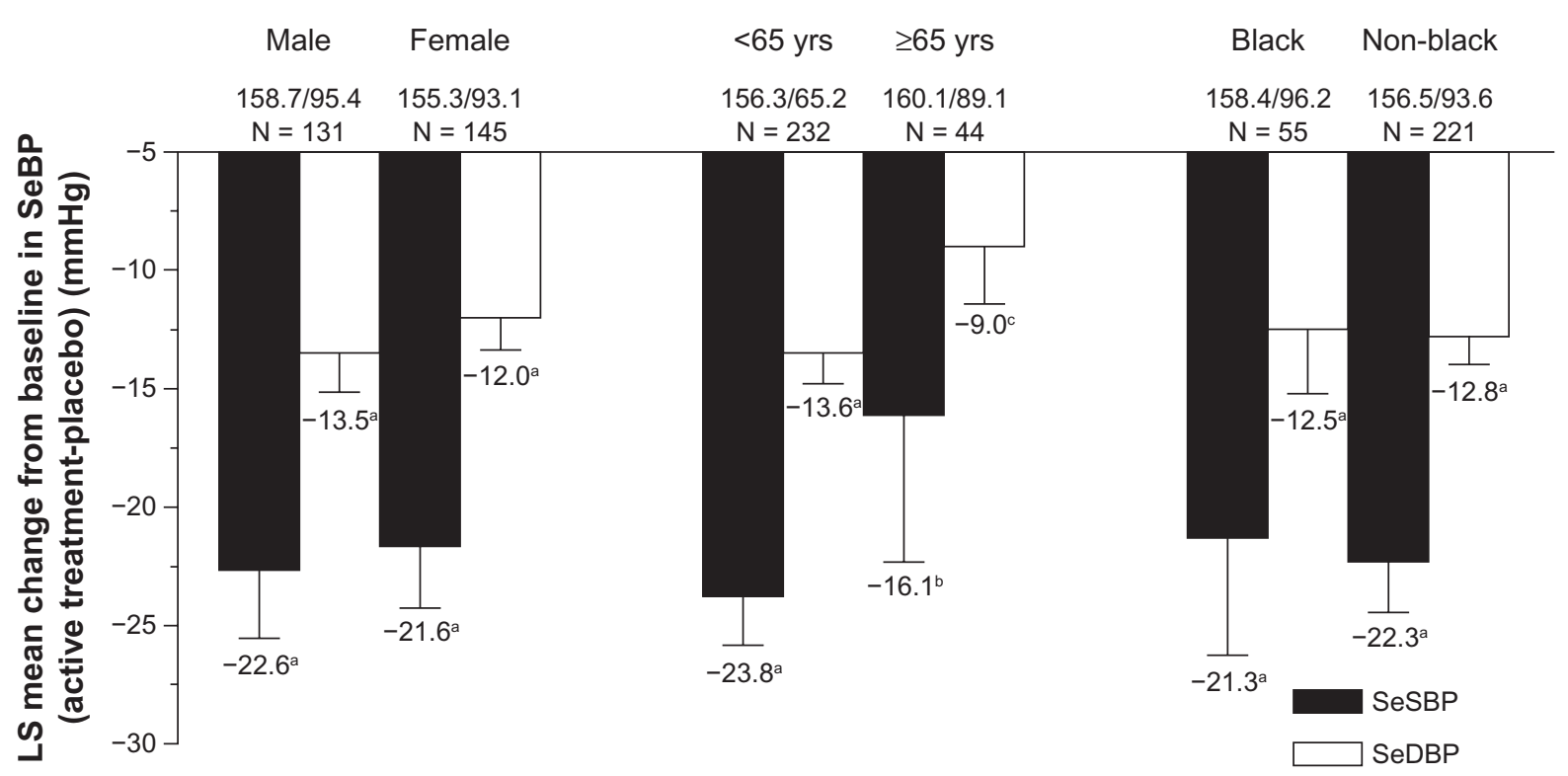

Figure 2 Results of a subgroup analysis of the BENIFORCE trial that reported the LS mean changes from baseline in SeBP in patients stratified according to sex, age, and race. ${ }^{23}$ Notes: ${ }^{a} P<0.000$ I vs placebo; ${ }^{b} P<0.05$ vs placebo; ${ }^{c} P<0.001$ vs placebo.

Abbreviations: BENIFORCE, Benicar Efficacy: New Investigative Findings Showed Olmesartan Medoxomil Safely and Effectively Reduced Blood Pressure Compared With Placebo in a Clinical Evaluation of Patients With Stage I and Stage 2 Hypertension; LS, least-squares; SeBP, seated cuff blood pressure; SeDBP, seated cuff diastolic blood pressure; SeSBP, seated cuff systolic blood pressure.

Reprinted from Oparil and Pimenta, J Clin Hypertens (Greenwich). 2010;12(1):3-13, with permission from John Wiley and Sons, copyright (C) 20I0.

$40 \mathrm{mg}(P<0.0001)$. The SeBP target of $<140 / 90 \mathrm{mmHg}$ $(<130 / 80 \mathrm{mmHg}$ for patients with diabetes) was achieved by $42.1 \%$ of patients who received OM/HCTZ $40 / 25 \mathrm{mg}$ compared with $24.8 \%$ of those treated with OM $40 \mathrm{mg}$.

\section{Assessment of 24-hour ambulatory BP efficacy with OM/HCTZ combination in patients with difficult-to-treat hypertension}

Two classes of patients with hypertension that is often difficult to treat are patients with type 2 diabetes mellitus (T2DM) and the elderly. Diabetes mellitus affects an estimated 25.8 million US residents of all ages. ${ }^{25}$ T2DM is associated with higher risks of $\mathrm{CV}$ disease, nephropathy, and retinopathy - hard endpoints that are associated closely with BP control. ${ }^{3,25}$ It is recommended that patients with T2DM and hypertension be treated to a more aggressive BP goal of $<130 / 80 \mathrm{mmHg},{ }^{26}$ which will often require two or more antihypertensive agents. ${ }^{3,27}$ In the Action to Control Cardiovascular Risk in Diabetes (ACCORD) trial, patients treated to an SBP of $119.3 \mathrm{mmHg}$ required an average of 3.4 medications, while patients treated to an $\mathrm{SBP}<133.3 \mathrm{mmHg}$ required an average of 2.1 medications. ${ }^{28}$ The elderly are more likely to have treatment-resistant hypertension due to physiological changes in the arterial vasculature that occur naturally with aging. ${ }^{29}$ Hypertension is more prominent in the elderly than in any other age group, with an estimated prevalence of $65 \%$ in men and $75 \%$ in women. ${ }^{30}$ Treating BP in the elderly has been associated with decreased incidence of various $\mathrm{CV}$ endpoints. ${ }^{3,31}$

BP naturally fluctuates and exhibits a diurnal variation over a 24-hour period..$^{32}$ In the morning hours, CV events are more common due to a morning surge in $\mathrm{BP} .{ }^{33}$ This increase in BP towards the end of the sleep period may be related to circadian upregulation of the RAS during the nighttime. ${ }^{34}$ Ambulatory BP monitoring (ABPM) can provide clinicians with additional information to diagnose hypertension, make more informed treatment decisions, and to gauge the effectiveness of antihypertensive therapy over 24 hours. ${ }^{35-37}$ BP control over a 24-hour dosing period has been demonstrated in several efficacy studies with $\mathrm{OM}+\mathrm{HCTZ} \cdot{ }^{38,39}$

\section{Patients with T2DM: the BENIFICIARY trial}

The BENIcar safety and efFICacy evaluatIon: an open-label, single-ARm, titration study in patients with hypertension and tYpe 2 diabetes (BENIFICIARY) study assessed 24-hour BP control in patients initiated on OM $20 \mathrm{mg}$ up-titrated to $\mathrm{OM}$ $40 \mathrm{mg}$, OM/HCTZ 40/12.5 mg, and OM/HCTZ 40/25 mg if BP was $\geq 120 / 70 \mathrm{mmHg} .{ }^{39} \mathrm{ABPM}$ was performed at baseline and at the end of week 12 . The primary endpoint was the change from baseline in mean 24-hour ambulatory SBP at week 12. At 12 weeks, 24-hour ambulatory BP was reduced 
by $20.4 / 11.1 \mathrm{mmHg}(P<0.0001$ vs baseline $)$, and ambulatory BP targets of $<130 / 80,<125 / 75$, and $<120 / 80 \mathrm{mmHg}$ were achieved by $61.6 \%, 47.1 \%$, and $39.0 \%$ of patients, respectively (Figure 3). ${ }^{39}$ Of special interest is that BP control was maintained during the last 6,4 , and 2 hours of the dosing interval when the normal morning rise in BP occurred. ${ }^{39}$ The SeBP reduction from baseline was $21.8 / 9.9 \mathrm{mmHg}$ in patients titrated to OM/HCTZ 40/25 mg intensified, and 41.1\% of patients achieved the cumulative guideline-recommended BP goal of $<130 / 80 \mathrm{mmHg}{ }^{40}$

\section{Elderly patients: the BeniSILVER trial}

The Benicar Efficacy: New Investigation Shows Olmesartan Medoxomil Treatment Increasingly Leads Various Elderly Populations to Safe BP Reductions (BeniSILVER) study was a 12-week, open-label, multicenter trial. ${ }^{38}$ This study was conducted in 178 patients aged $\geq 65$ years, and similar to BENIFICIARY, patients were initiated on OM $20 \mathrm{mg}$ and up-titrated to $\mathrm{OM} / \mathrm{HCTZ} 40 / 25 \mathrm{mg}$ in a stepwise fashion if SeBP was $\geq 120 / 70 \mathrm{mmHg}$. The primary endpoint was the change in mean 24-hour ambulatory SBP from baseline to week 12. At study end, mean 24-hour ambulatory BP decreased by $25.7 / 12.3 \mathrm{mmHg}$ ( $P<0.0001$ vs baseline) (Figure 4$)$ from a mean baseline BP of 148.8/80.9 $\mathrm{mmHg} .{ }^{38}$ After 12 weeks, the achievement of 24-hour ambulatory BP targets was also assessed in this study. Twentyfour hour ambulatory BP targets of $<130 / 80,<125 / 75$, and $<120 / 80 \mathrm{mmHg}$ were achieved by $73.3 \%, 56.7 \%$, and $44.0 \%$ of patients, respectively. ${ }^{38} \mathrm{BP}$ control was maintained throughout the 24-hour dosing interval with significant BP reductions from baseline observed during the last 6,4 , and 2 hours before re-dosing $(P<0.0001)$. A subgroup analysis in patients aged $>75$ years showed that 24-hour ambulatory BP targets of $<130 / 80,<125 / 75$, and $<120 / 80 \mathrm{mmHg}$ were achieved by $67.5 \%, 52.5 \%$, and $40.0 \%$ of patients, respectively. ${ }^{41}$ Based on these results, a treatment algorithm using $\mathrm{OM} \pm \mathrm{HCTZ}$ appears to be effective in providing 24-hour BP control in a range of patients with hypertension, including those with T2DM and the elderly. There is currently no consensus on ambulatory BP goal values; however, the American Heart Association recommends normal 24-hour, daytime, and nighttime ambulatory BP values in adults of $<130 / 80,<135 / 85$, and $<120 / 70 \mathrm{mmHg}$, respectively. ${ }^{42}$

\section{Safety and tolerability of OM and HCTZ}

A fixed-dose combination of $\mathrm{OM}+\mathrm{HCTZ}$ is associated with an overall adverse event (AE) rate that is similar to placebo, including when race or sex are considered. ${ }^{43}$ AEs

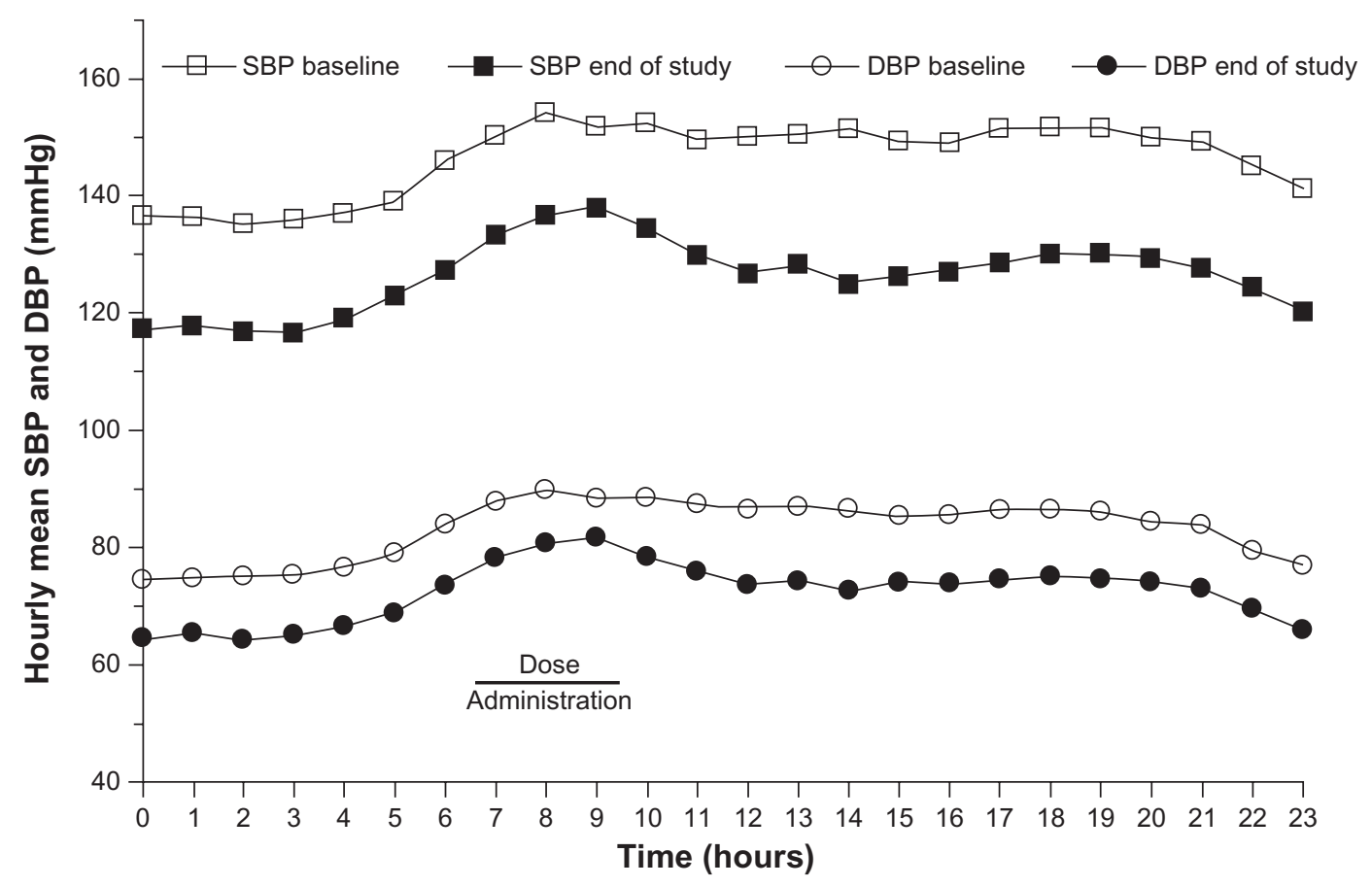

Figure 3 Hourly mean ambulatory blood pressure at baseline and end of study (week I2) in patients with diabetes treated with an olmesartan medoxomil/hydrochlorothiazidebased algorithm in the BENIFICIARY study. ${ }^{39}$

Neutel et al, Curr Med Res Opin, 2010;26(3):72I-728, copyright (C 2010, Informa Healthcare. Reproduced with permission of Informa Healthcare.

Abbreviations: BENIFICIARY, BENIcar safety and efFICacy evaluatlon: an open-label, single-ARm, titration study in patients with hypertension and tYpe 2 diabetes; DBP, diastolic blood pressure; SBP, systolic blood pressure. 


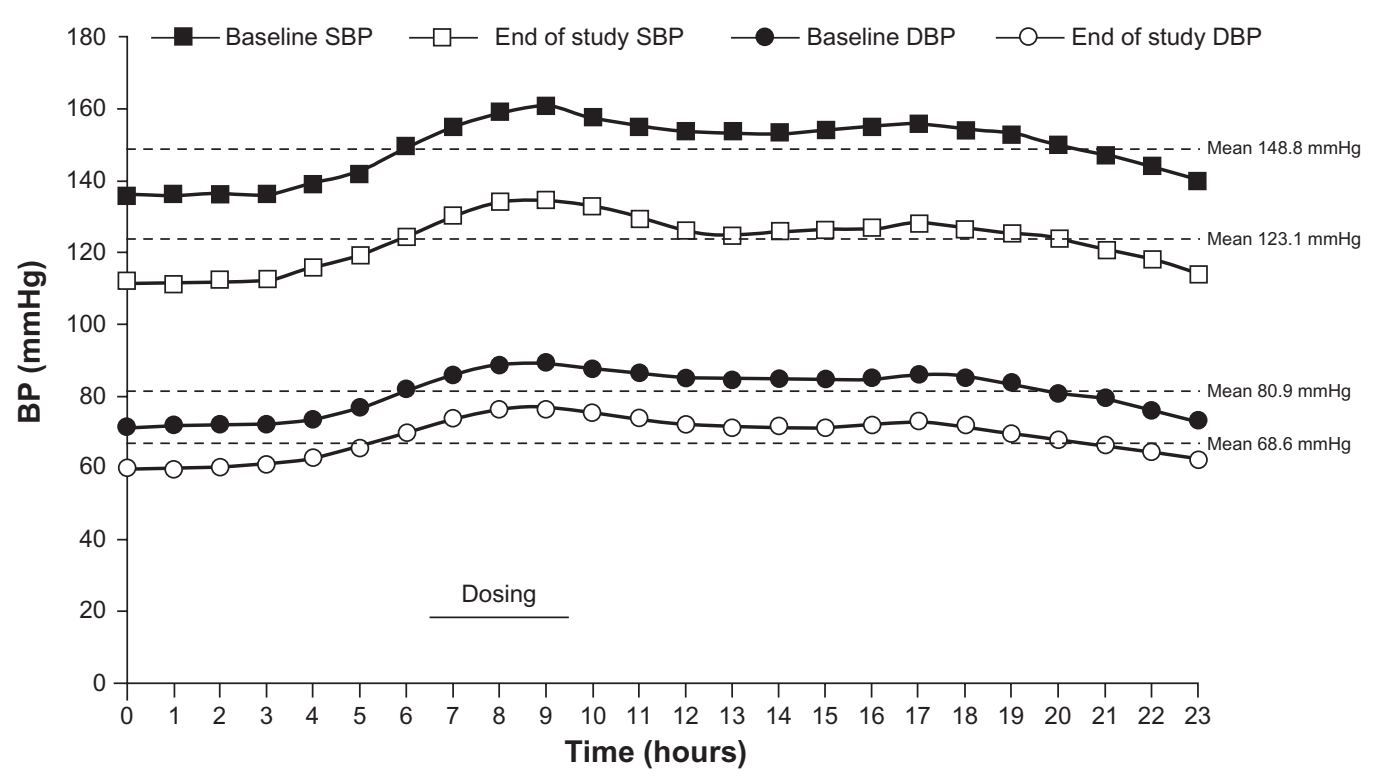

Figure 4 Hourly mean ambulatory BP at baseline and end of study (week 12) in patients aged $\geq 65$ years treated with an olmesartan medoxomil/hydrochlorothiazide-based algorithm in the BeniSILVER study. ${ }^{38}$

Reprinted from Kereiakes, et al. J Clin Hypertens (Greenwich). 2009; I I (8):4I I-42I, with permission from John Wiley and Sons, copyright (C) 20 I0.

Abbreviations: BeniSILVER, Benicar Efficacy: New Investigation Shows Olmesartan Medoxomil Treatment Increasingly Leads Various Elderly Populations to Safe BP Reductions; BP, blood pressure; DBP, diastolic blood pressure; SBP, systolic blood pressure.

that occurred at a higher frequency than placebo in $>2 \%$ of patients in pivotal trials include dizziness, upper respiratory tract infection, hyperuricemia, and nausea. ${ }^{43}$ Lending further support to placebo-like tolerability of OM + HCTZ are safety data reported in the BENIFORCE and BENIFICIARY trials. In BENIFORCE, the incidence of at least one $\mathrm{AE}$ across titration steps in the OM + HCTZ treatment arm ranged from $15.9 \%$ to $28.4 \%$ compared with $15.9 \%-26.2 \%$ during the placebo run-in period. ${ }^{22}$ Drug-related AEs ranged from $2.2 \%$ to $7.6 \%$ across titration steps in the $\mathrm{OM}+\mathrm{HCTZ}$ treatment arm compared with $2.1 \%-9.5 \%$ in the placebo arm. Most adverse effects were mild to moderate in intensity, with dizziness being the most commonly reported $\mathrm{AE}$ at $3.4 \% .{ }^{22}$ In the randomized double-blind period of the European study, treatment-emergent AEs (TEAEs) occurred in $11.8 \%-15.3 \%$ of patients across the treatment groups. ${ }^{24}$

In the BENIFICIARY study, where all patients had T2DM, the incidence of one or more TEAE was $13.5 \%-25.7 \%$ across all titrations steps, slightly lower than in BENIFORCE. ${ }^{39}$ Drug-related TEAEs ranged from $0.5 \%$ to $7.6 \%$ across the titration steps. The most commonly reported TEAE in BENIFICIARY was arthralgia and extremity pain at $2.1 \%{ }^{39}$ The occurrence of dizziness reported in BENIFICIARY was lower than in BENIFORCE at $0.7 \%{ }^{39}$

The treatment of hypertension in the elderly may result in relatively large BP reductions, especially in SBP. These large SBP reductions may be associated with dizziness and hypotension. In the BeniSILVER study, conducted in patients aged $>65$ years, $32.6 \%$ of patients reported an AE during the entire 12-week active treatment period, of which $11.8 \%$ were drug related. ${ }^{38}$ Incidences of drug-related dizziness and hypotension were $3.4 \%$ and $2.2 \%$, respectively.

The use of HCTZ as monotherapy has been associated with hypokalemia, hyponatremia, hyperuricemia, and elevated blood glucose. ${ }^{44}$ In a study by Izzo et al, the maximum dose of OM/HCTZ 40/25 mg was not found to be associated with clinically significant decreases in sodium or potassium. ${ }^{45}$ Glucose and uric acid levels were found to be increased, with a mean uric acid level of $7.38 \mathrm{mg} / \mathrm{dL}$ (baseline value $=6.03 \mathrm{mg} / \mathrm{dL}$ ) and mean glucose value of $109.0 \mathrm{mg} / \mathrm{dL}$ (baseline value $=103.9 \mathrm{mg} / \mathrm{dL}$ ). ${ }^{45}$ These were within normal limits and were not clinically significant events associated with these laboratory elevations. ${ }^{45}$

\section{Benefits beyond BP}

A number of ARBs have demonstrated the potential to provide benefits beyond their BP-lowering effects. In the Losartan Intervention for Endpoint Reduction (LIFE) trial, LOS monotherapy at $50 \mathrm{mg}$ up-titrated to LOS $100 \mathrm{mg}+\mathrm{HCTZ}$ $25 \mathrm{mg}$ over a period of 4 years resulted in a statistically significant decrease in the secondary endpoint of new-onset diabetes when compared with an atenolol $+\mathrm{HCTZ}$ regimen (13.0 vs 17.4 events $/ 1000$ patient-years; $P=0.001) .{ }^{46}$ Beneficial effects of an ARB + HCTZ combination on the rate of new-onset 
diabetes were also demonstrated in the Valsartan Antihypertensive Long-term Use Evaluation (VALUE) trial. Patients titrated to a maximum dose of valsartan $160 \mathrm{mg}+\mathrm{HCTZ} 25 \mathrm{mg}$ had significantly fewer events of new-onset diabetes compared with an AML treatment regimen over a period of 4 years $(32.1$ vs 41.1 events/1000 patient-years; $P<0.0001) .{ }^{47}$ New-onset diabetes was also a secondary endpoint in the VALUE trial. In the Randomized Olmesartan and Diabetes Microalbuminuria Prevention (ROADMAP) study, 4447 patients with T2DM were assigned to either OM $40 \mathrm{mg}$ or placebo for a median of 3.2 years. Additional drugs (but not angiotensin-converting enzyme inhibitors or ARBs) were used as necessary to attain BP control $(<130 / 80 \mathrm{mmHg}) .{ }^{48}$ The primary endpoint was the time to onset of microalbuminuria (MA). Overall, MA occurred in $8.2 \%$ of the OM group compared with $9.8 \%$ of the placebo group. The median time to onset of MA was 576 days for placebo compared with 722 days for OM (hazard ratio: $0.77 ; P=0.01$ ), a risk reduction of $23 \%$. Although no other study with ARBs has yielded similar results, ROADMAP provides evidence that pharmacological blockade with the ARB OM is highly effective in reducing the risk of developing MA and that the effect can be achieved through BP-dependent and BP-independent effects. ${ }^{49}$

\section{Rationale for combinations of HCTZ and OM}

Fixed-dose antihypertensive drug combination therapies that include a diuretic usually contain HCTZ rather than other agents such as chlorthalidone. Data reported by the Veterans Administration (VA) Cooperative study in 1967 is an early example whereby HCTZ demonstrated BP-reducing efficacy as well as reductions in $\mathrm{CV}$ events. ${ }^{50}$ In a cohort of highrisk male patients with DBP of 115-129 mmHg $(\mathrm{N}=143)$, HCTZ combined with reserpine and hydralazine reduced BP by an average of 43/30 $\mathrm{mmHg}$ after 24 months of treatment, and resulted in significantly reduced $\mathrm{CV}$ events compared with placebo ( 2 vs 27 total events; $P<0.001$ ). Three years later, the VA Cooperative Study reported data in a cohort of 380 male patients with lower risk diastolic hypertension (90-114 mmHg). ${ }^{51}$ An average reduction in BP of $27 / 17 \mathrm{mmHg}$ was achieved after 4 months of combination therapy. The estimated 5-year risk of a morbid event was reduced with HCTZbased treatment compared with placebo (18\% vs 55\%).

The preference for HCTZ over chlorthalidone may also be due to concerns about hypokalemia with chlorthalidone; ${ }^{52}$ however, hypokalemia is a class-wide effect for diuretics. ${ }^{53}$ The Multiple Risk Factor Intervention Trial (MRFIT) was a randomized primary prevention trial in 12,866 high-risk men with hypertension that compared a special intervention (SI) program (stepped-care combination therapy, smoking cessation counseling, and dietary advice) with usual care (UC) available within the community. ${ }^{54}$ Stepped-care therapy in the SI program began with a choice of HCTZ or chlorthalidone based on the preference at each treatment center. Reserpine, hydralazine, and guanethidine were able to be added on to the choice of diuretic, if required, to bring patients to the goal DBP of $<90 \mathrm{mmHg}$. After 7 years of follow-up, a statistically nonsignificant difference of $7.1 \%$ in mortality from coronary heart disease (CHD) was observed in the SI care group compared with UC. Of interest, with regards to hypokalemia, was a finding in predefined subgroups that hypertensive men with baseline echocardiogram abnormalities had higher CHD mortality in the SI group compared with UC (36 vs $21 \mathrm{CHD}$ deaths). This has led some to be concerned about the role that the choice of diuretics may have played in the increased mortality within this subgroup, particularly with regards to chlorthalidone.

In a study of 233 hypertensive men, Siegel et al sought to determine the potassium-wasting effects of HCTZ at $50 \mathrm{mg} /$ day, with and without potassium supplementation, or triamterene against chlorthalidone $50 \mathrm{mg}$ and placebo. ${ }^{55}$ After 2 months of treatment, serum potassium levels were decreased to $<3.5 \mathrm{mmol} / \mathrm{L}$ (threshold of hypokalemia) in $15 \%$ of patients treated with HCTZ $50 \mathrm{mg}$ without potassium supplementation vs $33 \%$ of patients treated with chlorthalidone $50 \mathrm{mg}(P<0.01) .{ }^{55}$ Severe hypokalemia, defined as serum potassium levels $<3.0 \mathrm{mmol} / \mathrm{L}$, occurred in $10 \%$ of patients taking HCTZ without supplementation and $20 \%$ of patients taking chlorthalidone, which was not a statistically significant difference. ${ }^{55}$ However, the dosage of HCTZ that was used in the study was greater than the maximum dosage (25 mg) used in single-pill combination formulations.

Pharmacokinetic considerations also inform the rationale for using HCTZ over chlorthalidone. Chlorthalidone has an estimated half-life ranging from 40 to 72 hours, ${ }^{52}$ while HCTZ has a half-life ranging from 6 to 15 hours. ${ }^{44}$ In select patient populations with renal impairment, avoiding medications with long half-lives may help to reduce the likelihood of AEs. Drug labels for both HCTZ and chlorthalidone advise against administering to patients with renal impairment, and neither diuretic appears in the Beers criteria for inappropriate medication use in the elderly. ${ }^{56}$ The shorter half-life of HCTZ could potentially be a concern with regards to 24-hour BP control. However, the antihypertensive efficacy of OM/HCTZ combination therapy has been shown to be maintained throughout the 24-hour dosing interval in a variety of patient subgroups. ${ }^{57}$ 


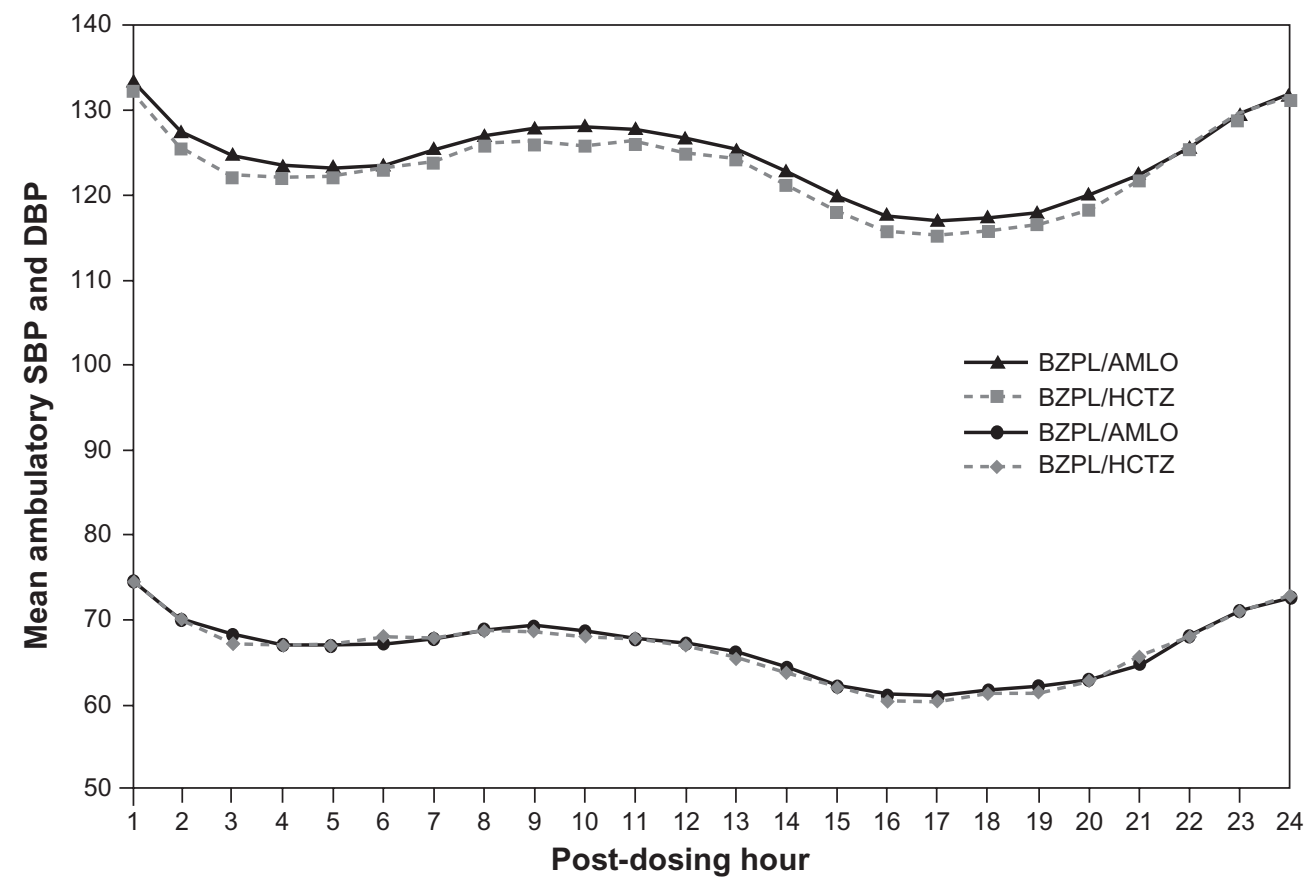

Figure 5 Mean hourly BP values according to treatment group during the 24-hour dosing interval, reported in an ambulatory BP monitoring substudy of the ACCOMPLISH trial.59 Reprinted from Jamerson, et al. Efficacy and Duration of Benazepril Plus Amlodipine or Hydrochlorthiazide on 24-Hour Ambulatory Systolic Blood Pressure Control. Hypertension. 201 1;57(2): 174-179, with permission from Wolters Kluwer Health, copyright () 201I.

Abbreviations: ACCOMPLISH, Avoiding Cardiovascular Events through Combination Therapy in Patients Living with Systolic Hypertension; AMLO, amlodipine; BP, blood pressure; BZPL, benazepril; DBP, diastolic blood pressure; HCTZ, hydrochlorothiazide; SBP, systolic blood pressure.

Data from the ALLHAT study suggest that chlorthalidone may increase the incidence of new-onset diabetes..$^{58}$ When compared with AML and lisinopril, chlorthalidone-treated patients had $43 \%$ and $65 \%$ higher incidences of new-onset diabetes, respectively. ${ }^{58}$ While there were no differences between chlorthalidone and AML or lisinopril in CV outcomes, the trial duration would not have been long enough to account for $\mathrm{CV}$ outcomes in patients with new-onset diabetes, as $\mathrm{CV}$ effects would not become manifest in the short timeframe of the study. ${ }^{58}$ Head-to-head outcomes studies between chlorthalidone and HCTZ have not been conducted, and thus it remains to be seen whether HCTZ would have had similar increases in new-onset diabetes.

An ABPM substudy of the Avoiding Cardiovascular Events through Combination Therapy in Patients Living with Systolic Hypertension (ACCOMPLISH) trial was recently conducted to identify any differences in 24-hour BP control between BEN plus AML and BEN plus HCTZ after 2 years of treatment. ${ }^{59}$ Mean 24-hour, daytime, and nighttime $\mathrm{BP}$ values were not significantly different between the two treatment groups (Figure 5); BP control rates were $>80 \%$ in both groups..$^{59}$ This indicates that 24-hour BP control is similar between the two treatment groups and supports the original conclusions of the ACCOMPLISH investigators that the improvement in $\mathrm{CV}$ outcomes seen in the AML-based regimen is most likely due to other putative cardioprotective properties of combining a RAS blocker with AML. ${ }^{60} \mathrm{AML}$ has a terminal elimination half-life ranging from 30 to 50 hours, ${ }^{61}$ very similar to chlorthalidone; however, the longer half-life conferred no additional benefit over HCTZ with regards to 24-hour BP control. ${ }^{59}$

The overall preference of HCTZ over chlorthalidone may simply be due to the availability of HCTZ as a component of fixed-dose, single-pill combinations. There are currently no fixed-dose ARB + chlorthalidone single-pill combination products available.

In view of the recent clinical evidence that demonstrates the efficacy and safety of treatment regimens based on $\mathrm{OM}+\mathrm{HCTZ}$, there is no reason that HCTZ should not remain as a preferred treatment option for use in combination with ARBs such as OM. However, there remains an unmet need for head-to-head outcomes studies that compare the relative efficacy and tolerability of HCTZ and chlorthalidone in order to provide evidence for informing clinical guidelines. ${ }^{53}$

\section{Conclusion}

ARBs provide excellent efficacy and tolerability and are frequently used as first-line therapy, alone or in combination with diuretics. The combination of $\mathrm{OM} / \mathrm{HCTZ}$ has been shown to be an effective and well tolerated treatment option 
that provides BP-lowering efficacy and improvements in BP control in patients with hypertension. BP reduction achieved through combination therapy has been associated with improvements in CV morbidity and mortality. ${ }^{62}$ The clinical evidence discussed in this review provides a rationale for the use of OM/HCTZ combination therapy as an antihypertensive treatment strategy, regardless of patient age, sex, or race, or patients with common comorbidities such as diabetes.

\section{Acknowledgments/Disclosure}

Robert Schupp, PharmD, and Christopher J Jones, PhD, of inScience Communications, a Wolters Kluwer business, provided medical writing support, which was funded by Daiichi Sankyo, Inc.

Henry A Punzi, MD, has received grant/research support from Abbott Laboratories, Boehringer Ingelheim, Daiichi Sankyo, Inc, Forest Laboratories, Gilead, NIH, and Takeda Pharmaceutical Company Limited. Dr Punzi has served on the Speaker's Bureau for Abbott Laboratories, Boehringer Ingelheim, Bristol-Myers Squibb, and Forest Laboratories.

\section{References}

1. Egan BM, Zhao Y, Axon RN. US trends in prevalence, awareness, treatment, and control of hypertension, 1988-2008. JAMA. 2010;303(20): 2043-2050.

2. Rosendorff C, Black HR, Cannon CP, et al; American Heart Association Council for High Blood Pressure Research; American Heart Association Council on Clinical Cardiology; American Heart Association Council on Epidemiology and Prevention. Treatment of hypertension in the prevention and management of ischemic heart disease: a scientific statement from the American Heart Association Council for High Blood Pressure Research and the Councils on Clinical Cardiology and Epidemiology and Prevention. Circulation. 2007;115(21):2761-2788.

3. Chobanian AV, Bakris GL, Black HR, et al; National Heart, Lung, and Blood Institute Joint National Committee on Prevention, Detection, Evaluation, and Treatment of High Blood Pressure; National High Blood Pressure Education Program Coordinating Committee. The Seventh Report of the Joint National Committee on Prevention, Detection, Evaluation, and Treatment of High Blood Pressure: the JNC 7 report. JAMA. 2003;289(19):2560-2572.

4. Black HR, Elliott WJ, Grandits G, et al; CONVINCE Research Group. Principal results of the Controlled Onset Verapamil Investigation of Cardiovascular End Points (CONVINCE) trial. JAMA. 2003;289(16):2073-2082.

5. Mori H, Ukai H, Yamamoto H, et al. Current status of antihypertensive prescription and associated blood pressure control in Japan. Hypertens Res. 2006;29(3):143-151.

6. Qvarnstrom M, Wettermark B, Ljungman C, et al. Antihypertensive treatment and control in a large primary care population of 21167 patients. J Hum Hypertens. 2011;25(8):484-491.

7. Kjeldsen SE, Os I, Hoieggen A, Beckey K, Gleim GW, Oparil S. Fixed-dose combinations in the management of hypertension: defining the place of angiotensin receptor antagonists and hydrochlorothiazide. Am J Cardiovasc Drugs. 2005;5(1):17-22.

8. Mylan Pharmaceuticals. Hydrochlorothiazide capsule. Available at: http://dailymed.nlm.nih.gov/dailymed/drugInfo.cfm?id=10039. Accessed February 24, 2011.
9. Duarte JD, Cooper-DeHoff RM. Mechanisms for blood pressure lowering and metabolic effects of thiazide and thiazide-like diuretics. Expert Rev Cardiovasc Ther. 2010;8(6):793-802.

10. Oparil S, Williams D, Chrysant SG, Marbury TC, Neutel J. Comparative efficacy of olmesartan, losartan, valsartan, and irbesartan in the control of essential hypertension. J Clin Hypertens (Greenwich). 2001;3(5): 283-291, 318.

11. Weir MR, Punzi HA, Flack JM, et al. A randomized, double-blind, forced-titration study to compare olmesartan medoxomil versus losartan potassium in patients with stage 1 and 2 hypertension. Postgrad Med. 2011;123(1):80-87.

12. Giles TD, Oparil S, Silfani TN, Wang A, Walker JF. Comparison of increasing doses of olmesartan medoxomil, losartan potassium, and valsartan in patients with essential hypertension. J Clin Hypertens (Greenwich). 2007;9(3):187-195.

13. Giles TD, Oparil S, Wang A, Dubiel R. An evaluation of the efficacy of olmesartan medoxomil in Black patients with hypertension. $\mathrm{J} \mathrm{Am}$ Soc Hypertens. 2009;3(6):395-402.

14. White WB, Weber MA, Sica D, et al. Effects of the angiotensin receptor blocker azilsartan medoxomil versus olmesartan and valsartan on ambulatory and clinic blood pressure in patients with stages 1 and 2 hypertension. Hypertension. 2011;57(3):413-420.

15. Le MT, Pugsley MK, Vauquelin G, Van Liefde I. Molecular characterisation of the interactions between olmesartan and telmisartan and the human angiotensin II AT1 receptor. Br J Pharmacol. 2007;151(7): 952-962.

16. Zannad F, Fay R. Blood pressure-lowering efficacy of olmesartan relative to other angiotensin II receptor antagonists: an overview of randomized controlled studies. Fundam Clin Pharmacol. 2007;21(2):181-190.

17. BENICAR (olmesartan medoxomil) US prescribing information. Parsippany, NJ: Daiichi Sankyo, Inc; 2010.

18. Kreutz R, Bolbrinker J, Huber M. Pharmacokinetics of olmesartan medoxomil plus hydrochlorothiazide combination in healthy subjects. Clin Drug Invest. 2006;26(1):29-34.

19. Mizuno M, Sada T, Ikeda M, et al. Pharmacology of CS-866, a novel nonpeptide angiotensin II receptor antagonist. Eur J Pharmacol. 1995; 285(2):181-188.

20. Chrysant SG, Weber MA, Wang AC, Hinman DJ. Evaluation of antihypertensive therapy with the combination of olmesartan medoxomil and hydrochlorothiazide. Am J Hypertens. 2004;17(3):252-259.

21. Kereiakes DJ, Neutel JM, Punzi HA, Xu J, Lipka LJ, Dubiel R. Efficacy and safety of olmesartan medoxomil and hydrochlorothiazide compared with benazepril and amlodipine besylate. Am J Cardiovasc Drugs. 2007; 7(5):361-372.

22. Oparil S, Chrysant SG, Kereiakes D, et al. Results of an olmesartan medoxomil-based treatment regimen in hypertensive patients. J Clin Hypertens (Greenwich). 2008;10(12):911-921.

23. Oparil S, Pimenta E. Efficacy of an olmesartan medoxomil-based treatment algorithm in patients stratified by age, race, or sex. J Clin Hypertens (Greenwich). 2010;12(1):3-13.

24. Rump LC, Girerd X, Sellin L, Stegbauer J. Effects of high dose olmesartan medoxomil plus hydrochlorothiazide on blood pressure control in patients with grade 2 and grade 3 hypertension. J Hum Hypertens. 2011;25(9):565-574.

25. Centers for Disease Control and Prevention. National Diabetes Statistics, 2011. Available at: http://diabetes.niddk.nih.gov/DM/PUBS/statistics/ DM_Statistics.pdf. Accessed February 22, 2011.

26. American Diabetes Association. Standards of medical care in diabetes 2011. Diabetes Care. 2011;34 Suppl 1:S11-S61.

27. Mancia G, De Backer G, Dominiczak A, et al. 2007 ESH-ESC Practice Guidelines for the Management of Arterial Hypertension: ESH-ESC Task Force on the Management of Arterial Hypertension. J Hypertens. 2007;25(9):1751-1762.

28. Cushman WC, Evans GW, Byington RP, et al. Effects of intensive blood-pressure control in type 2 diabetes mellitus. N Engl J Med. 2010; 362(17):1575-1585. 
29. Chobanian AV. Clinical practice. Isolated systolic hypertension in the elderly. N Engl J Med. 2007;357(8):789-796.

30. Roger VL, Go AS, Lloyd-Jones DM, et al. Heart disease and stroke statistics - 2011 update: a report from the American Heart Association. Circulation. 2011;123(4):e18-e209.

31. SHEP Cooperative Research Group. Prevention of stroke by antihypertensive drug treatment in older persons with isolated systolic hypertension. Final results of the Systolic Hypertension in the Elderly Program (SHEP). JAMA. 1991;265(24):3255-3264.

32. Kario K, Pickering TG, Umeda Y, et al. Morning surge in blood pressure as a predictor of silent and clinical cerebrovascular disease in elderly hypertensives: a prospective study. Circulation. 2003;107(10): 1401-1406.

33. Gosse P, Lasserre R, Minifie C, Lemetayer P, Clementy J. Blood pressure surge on rising. J Hypertens. 2004;22(6):1113-1118.

34. Hermida RC, Ayala DE, Fernandez JR, Portaluppi F, Fabbian F, Smolensky MH. Circadian rhythms in blood pressure regulation and optimization of hypertension treatment with ACE inhibitor and ARB medications. Am J Hypertens. 2011;24(4):383-391.

35. Chavanu K, Merkel J, Quan AM. Role of ambulatory blood pressure monitoring in the management of hypertension. Am J Health Syst Pharm. 2008;65(3):209-218.

36. Pickering TG, White WB. ASH Position Paper: Home and ambulatory blood pressure monitoring. When and how to use self (home) and ambulatory blood pressure monitoring. J Clin Hypertens (Greenwich). 2008;10(11):850-855.

37. Punzi HA. Why ambulatory blood pressure monitoring? Am J Health Syst Pharm. 1998;55 Suppl 3:S12-S16.

38. Kereiakes DJ, Neutel J, Stoakes KA, et al. The effects of an olmesartan medoxomil-based treatment algorithm on 24-hour blood pressure levels in elderly patients aged 65 and older. $J$ Clin Hypertens (Greenwich). 2009;11(8):411-421.

39. Neutel JM, Kereiakes DJ, Waverczak WF, Stoakes KA, Xu J, Shojaee A. Effects of an olmesartan medoxomil based treatment algorithm on 24-hour blood pressure control in patients with hypertension and type 2 diabetes. Curr Med Res Opin. 2010;26(3):721-728.

40. Kereiakes D, Neutel J. Seated cuff blood pressure-lowering efficacy of an olmesartan medoxomil-based treatment regimen in patients with type 2 diabetes mellitus. Drugs R D. 2011;11(3):1-7.

41. Neutel J, Kereiakes DJ, Stoakes KA, Maa J, Shojaee A, Waverczak WF Blood pressure-lowering efficacy of an olmesartan medoxomil/ hydrochlorothiazide-based treatment algorithm in elderly patients (age $\geq 65$ years) stratified by age, sex and race: subgroup analysis of a 12-week, open-label, single-arm, dose-titration study. Drugs Aging. 2011;28(6):477-490

42. Pickering TG, Hall JE, Appel LJ, et al. Recommendations for blood pressure measurement in humans and experimental animals: part 1: blood pressure measurement in humans: a statement for professionals from the Subcommittee of Professional and Public Education of the American Heart Association Council on High Blood Pressure Research. Circulation. 2005;111(5):697-716.

43. Daiichi Sankyo, Inc. Benicar HCT (olmesartan medoxomil and hydrochlorothiazide) tablet, film coated. 2007. Available at: http://www benicar.com/pdf/prescribing_information_HCT.pdf. Accessed March 17, 2011.

44. Benicar $\mathrm{HCT}^{\circledR}$ (olmesartan medoxomil and hydrochlorothiazide). US prescribing information. Parsippany, NJ: Daiichi Sankyo, Inc; 2007.

Integrated Blood Pressure Control

\section{Publish your work in this journal}

Integrated Blood Pressure Control is an international, peer-reviewed open-access journal focusing on the integrated approach to managing hypertension and risk reduction. Treating the patient and comorbidities together with diet and lifestyle modification and optimizing healthcare resources through a multidisciplinary team approach constitute key
45. Izzo JL Jr, Neutel JM, Silfani T, Dubiel R, Walker F. Efficacy and safety of treating stage 2 systolic hypertension with olmesartan and olmesartan/ HCTZ: results of an open-label titration study. J Clin Hypertens (Greenwich). 2007;9(1):36-44.

46. Dahlof B, Devereux RB, Kjeldsen SE, et al. Cardiovascular morbidity and mortality in the Losartan Intervention For Endpoint reduction in hypertension study (LIFE): a randomised trial against atenolol. Lancet. 2002;359(9311):995-1003.

47. Julius S, Kjeldsen SE, Weber M, et al. Outcomes in hypertensive patients at high cardiovascular risk treated with regimens based on valsartan or amlodipine: the VALUE randomised trial. Lancet. 2004; 363(9426):2022-2031.

48. Haller $\mathrm{H}$, Ito $\mathrm{S}$, Izzo JL Jr, et al. Olmesartan for the delay or prevention of microalbuminuria in type 2 diabetes. $N$ Engl J Med. 2011;364(10): 907-917.

49. Grassi G. The ROADMAP trial: olmesartan for the delay or prevention of microalbuminuria in type 2 diabetes. Expert Opin Pharmacother. 2011;12(15):2421-2424

50. VA Cooperative Study Group. Effects of treatment on morbidity in hypertension. JAMA. 1967;202:1028-1034.

51. VA Cooperative Study Group. Effects of treatment on morbidity in hypertension. JAMA. 1970;213:1143-1152.

52. Carter BL, Ernst ME, Cohen JD. Hydrochlorothiazide versus chlorthalidone: evidence supporting their interchangeability. Hypertension. 2004;43(1):4-9.

53. Neff KM, Nawarskas JJ. Hydrochlorothiazide versus chlorthalidone in the management of hypertension. Cardiol Rev. 2010;18(1):51-56.

54. Multiple risk factor intervention trial. Risk factor changes and mortality results. Multiple Risk Factor Intervention Trial Research Group. JAMA. 1982;248(12):1465-1477.

55. Siegel D, Hulley SB, Black DM, et al. Diuretics, serum and intracellular electrolyte levels, and ventricular arrhythmias in hypertensive men. JAMA. 1992;267(8):1083-1089.

56. Fick DM, Cooper JW, Wade WE, Waller JL, Maclean JR, Beers MH Updating the Beers criteria for potentially inappropriate medication use in older adults: results of a US consensus panel of experts. Arch Intern Med. 2003;163(22):2716-2724.

57. Neutel JM, Kereiakes DJ. An olmesartan medoxomil-based treatment algorithm is effective in achieving 24-hour BP control in patients with type 2 diabetes mellitus, regardless of age, race, sex, or severity of hypertension: subgroup analysis of the BENIFICIARY study. Am J Cardiovasc Drugs. 2010;10(5):289-303.

58. Punzi HA, Punzi CF. Metabolic issues in the Antihypertensive and Lipid-Lowering Heart Attack Trial Study. Curr Hypertens Rep. 2004; 6(2):106-110.

59. Jamerson KA, Devereux R, Bakris GL, et al. Efficacy and duration of benazepril plus amlodipine or hydrochlorthiazide on 24-hour ambulatory systolic blood pressure control. Hypertension. 2011;57(2):174-179.

60. Jamerson K, Weber MA, Bakris GL, et al. Benazepril plus amlodipine or hydrochlorothiazide for hypertension in high-risk patients. $N$ Engl J Med. 2008;359(23):2417-2428.

61. Major Pharmaceuticals. Amlodipine besylate tablet. 2009. Available at: http://nccs-dailymed-1.nlm.nih.gov/dailymed/drugInfo. cfm?id=11136\#nlm42230-3. Accessed March 17, 2011.

62. Tribenzor ${ }^{\mathbb{B}}$ (olmesartan medoxomil, amlodipine, hydrochlorothiazide) US prescribing information. Parsippany, NJ: Daiichi Sankyo, Inc; 2011.

\section{Dovepress}

features of the journal. This journal is indexed on American Chemical Society's Chemical Abstracts Service (CAS). The manuscript management system is completely online and includes a very quick and fair peerreview system, which is all easy to use. Visit http://www.dovepress.com/ testimonials.php to read real quotes from published authors. 